\title{
Next-generation electrocaloric and pyroelectric materials for solid-state electrothermal interconversion
}

S. Pamir Alpay, Joseph Mantese, Susan Trolier-McKinstry, Qiming Zhang, and Roger W. Whatmore

\begin{abstract}
Thin-film electrocaloric and pyroelectric electrothermal interconversion energy sources have recently emerged as viable means for primary and auxiliary solid-state cooling and power generation. Two significant advances have facilitated this development: (1) the formation of high-quality polymeric and ceramic thin films with figures of merit that project system-level performance as a large percentage of Carnot efficiency and (2) the ability of these newer materials to support larger electric fields, thereby permitting operation at higher voltages. This makes the power electronic architectures more favorable for thermal to electric interconversion. Current research targets to adequately address commercial device needs include reduction of parasitic losses, increases in mechanical robustness, and the ability to form nearly free-standing elements with thicknesses in the range of 1-10 $\mu \mathrm{m}$. This article describes the current state-ofthe-art materials, thermodynamic cycles, and device losses and points toward potential lines of research that would lead to substantially better figures of merit for electrothermal interconversion.
\end{abstract}

Keywords: Material type-polymer (143), Material type-ceramic (121), Functionality-energy generation (189), Functionality-ferroelectric (192), Material form-film (231), Transport-ferroelectricity (288)

\section{Fundamentals of ferroelectrics materials: Pyroelectrics and Electrocalorics}

It has long been known that, when heated, materials such as the borosilicate tourmaline have the ability to attract objects such as pieces of feather, pollen, and cloth. This is due to the appearance of a surface charge in response to a temperature change. The history of this phenomenon, which is known as the pyroelectric effect $(\mathrm{PE})$, was charted by Lang, ${ }^{1}$ from its first description by 
Theophrastus in the 4th century BC, through studies by various well-known scientists (including Sir David Brewster, Lord William Thomson Kelvin and the brothers [Pierre and Jacques Curie]), to its widespread use in infrared sensing and thermal imaging., ${ }^{2,3}$

Dielectrics whose structures possess both a unique axis of symmetry and lack a center of symmetry (i.e., that are "polar") display a spontaneous polarization $\left(P_{\mathrm{S}}\right)$ and will exhibit a $\mathrm{PE}$ due to temperature-induced changes in $P_{\mathrm{S}}$. These variations in $P_{\mathrm{S}}$ result in uncompensated charge appearing along surfaces that have a component normal to the polar axis, generating a net voltage across the dielectric. If the surfaces are provided with electrodes that are connected through an external circuit, this surface charge can cause a current to flow, potentially resulting in useful work. In the absence of an applied electric field or applied stress, the pyroelectric coefficient $p(T)$ is defined as the rate of change of spontaneous polarization with temperature such that $p(T)=\mathrm{d} P_{\mathrm{S}} / \mathrm{d} T$. If electrodes are applied to the major faces perpendicular to the polar axis, as illustrated in Figure 1a, and the temperature is changed at a rate $\mathrm{d} T / \mathrm{d} t$, then the short-circuit pyroelectric current $i_{\mathrm{p}}$ is

$$
i_{\mathrm{p}}=A p(T) \frac{\mathrm{d} T}{\mathrm{~d} t}
$$

The converse of the pyroelectric effect is called the electrocaloric effect (ECE; see Figure 1b). Here, an electric field applied to a polar dielectric causes a change in temperature in the material. Conceptually, the ECE is somewhat harder to grasp than the PE, but it is analogous to the changes in temperature and entropy that occur when a gas is compressed or in a rubber band when it is stretched. The entropy and corresponding temperature changes are due to the relative movement of the ions in the structure under the applied field and, hence, changes in order. Over the past 10 years, there has been a considerable upsurge of interest in the technological applications of the PE for the recovery of electrical energy from waste heat ${ }^{4}$ (to power autonomous sensors or improve the overall efficiency of combustion engines, for example) and of the ECE in new cooling systems ${ }^{5,6}$ (to eliminate the use of liquid refrigerants). The two effects are intimately related. 
They really are "two sides of the same thermodynamic coin," and there is thus considerable commonality in the technological issues that will be encountered in both types of applications. The purpose of this article is to review the effects and their applications, and to explore the developments needed to bring the materials to successful exploitation.

Ferroelectrics ${ }^{7}$ form a special class of polar dielectrics in which the direction of the polar axis can be switched between equivalent, crystallographically related stable states by an electric field, which leads to the phenomenon of ferroelectric hysteresis (Figure 1c). Most ferroelectrics exhibit a transition to a higher-symmetry, nonferroelectric (paraelectric) phase as the temperature is raised. At this transition temperature (the Curie temperature, $T_{\mathrm{C}}$ ), the spontaneous polarization, $P_{\mathrm{S}}$, decreases to zero (see Figure 1d). The gradient of the $P_{\mathrm{S}}$ versus $T$ curve at any temperature is the pyroelectric coefficient, $p(T)$. This coefficient can be quite high in ferroelectrics, even well below $T_{\mathrm{C}}$, with the strongest pyroelectric effects typically being shown by ferroelectrics near their transitions. The magnitudes of the dielectric, elastic, electromechanical, and electrothermal properties depend strongly on the external stimulus near $T_{\mathrm{C}}$. This is illustrated in Figure 1e for the relative dielectric constant, which becomes significantly tunable by an applied electric field $E$ around the ferroelectric transition.

Examples of the crystal structures of ferroelectrics that are important for pyroelectric and electrocaloric applications are illustrated in Figure 2. These include the perovskites $\mathrm{PbTiO}_{3}$ (PT; see the structure in Figure 2a) and $\mathrm{Pb}\left(\mathrm{Mg}_{1 / 3} \mathrm{Nb}_{2 / 3}\right) \mathrm{O}_{3}(\mathrm{PMN})$, especially when in solid solution with PT (see Figure 2b). PT undergoes a transition from the cubic paraelectric state to a tetragonal ferroelectric state at $490^{\circ} \mathrm{C}$. PMN is a rhombohedral ferroelectric below about $0^{\circ} \mathrm{C}$. PMN is an important example of a ferroelectric relaxor, in which the phase transition is diffuse and the permittivity peak at the transition is broad and strongly dependent on the frequency of measurement. Figure $2 \mathrm{c}$ shows the crystal structure of $\mathrm{LiTaO}_{3}$ (LTO). Above the ferroelectric phase transition of $\sim 618^{\circ} \mathrm{C}^{8,9}$ (depending on stoichiometry), the Li atom sits in a high-symmetry position (space 
group $R \overline{3} c$ ). Below $T_{\mathrm{C}}$, the $\mathrm{Li}$ atom displaces to one of two positions, enabling ferroelectricity. PT (usually modified with additions of $\mathrm{Ca}$ ) and LTO are materials widely used in pyroelectric infrared sensors ${ }^{2}$. Polymeric materials can also exhibit ferroelectricity. Particularly important examples are poly(vinylidene fluoride) (PVDF) (see Figure 2d for its polar structure) and the copolymeric material poly(vinylidene fluoride-co-trifluoroethyene) [P(VDF-TrFE)]. Terpolymers of $\mathrm{P}(\mathrm{VDF}-\mathrm{TrFE})$ with cholorfluoroethylene (CFE) are important for ECE applications and can exhibit ferroelectric relaxor behavior.

Derivation of the pyroelectric and electrocaloric coefficients follows from thermodynamic analysis. The total free energy density of a dielectric is

$$
G=U-T S-X x-E D,
$$

where $U, T, S, X, x$, and $E$ are the internal energy of the system, temperature, entropy, stress, strain, and applied electric field, respectively. $D$ is the dielectric displacement, defined as $D=\varepsilon_{0} E+P_{\mathrm{S}}$, where $\varepsilon_{0}$ is the dielectric permittivity of a vacuum. The correlation between these quantities is best described using a Heckmann diagram, as shown in Figure 1f. This diagram describes the material properties connecting the intensive thermal, electrical, and mechanical variables $E$, $X$ and $T$ (outer triangle) to the extensive variables $D, x$ and $S$ (inner triangle). The pyroelectric coefficient $p$ is given by:

$$
p(T, E, x)=\left(\frac{\partial S}{\partial E}\right)_{T, X}=\left(\frac{\partial P^{0}}{\partial T}\right)_{E, X}
$$

where $P^{0}$ is the total equilibrium polarization. By computing values of the total heat capacity $C_{\mathrm{E}, \mathrm{X}}$ and $P^{0}$ as functions of $T, E$, and $x$, a field-induced adiabatic temperature change can be determined as

$$
\Delta T(T, E, X)=-T \int_{E_{1}}^{E_{2}} \frac{1}{C_{E, X}}\left(\frac{\partial P^{0}}{\partial T}\right) \mathrm{d} E,
$$

where $E_{2}-E_{1}=\Delta E$ is the difference in the applied electric field. Complete thermodynamic derivations of the changes in entropy for linear dielectrics and polar dielectrics that display a first- or second-order paraelectric-ferroelectric (FE) phase transformation are given elsewhere. ${ }^{10,11}$ 


\section{Thermal-electrical energy interconversion using ferroelectrics:}

\section{Thermodynamic cycles}

Just as the entropy changes inherent in a body of gas can be harnessed to do useful mechanical work as the gas is heated and cooled, so can the entropy changes in a ferroelectric material close to a phase transition be used to extract electrical energy or, alternatively, to provide refrigeration.

Olsen et al. ${ }^{12}$ reviewed the different thermodynamic cycles that can be employed to extract electrical energy from waste heat using ferroelectric materials (see Figure 3 which illustrates the principal thermodynamic cycles, expressed in $D$ vs $E$, which have been used in pyroelectric energy recovery and harvesting, and simple circuits which can be used to implement them). Many of these have direct counterparts in the thermodynamic cycles developed for use in heat engines in the 19th century. Frood ${ }^{13}$ was the first to point out that it is possible to convert heat directly into electricity by using the temperature behavior of a dielectric material under an applied field. He proposed a cycle of electrical displacement versus field across a capacitor $(C)$ that is analogous to the Carnot cycle and is illustrated in Figure 3a. $E$ is increased while $C$ is in contact with a heat sink at $T_{1}$. At point 2, $C$ is thermally isolated and $E$ increased so $C$ moves adiabatically to $T_{2}$ (point 3). It is then placed in contact with a heat source at $T_{2}$ and $E$ reduced to $\mathrm{p}$ taking the system to point 4 , after which $C$ is thermally isolated and E reduced so $C$ returns adiabatically to point 2 . The Carnot cycle efficiency $\left(\eta_{\text {Carnot }}\right)$ is independent of heat engine design and is given by

$$
\eta_{\text {Carnot }}=1-\frac{T_{1}}{T_{2}}
$$

where $T_{1}$ and $T_{2}$ are the temperatures of the heat sink and heat source, respectively.

The electrical work output per cycle from a ferroelectric Carnot cycle is small because of the limitations of the electrocaloric effect. van der Ziel ${ }^{14}$ and Gonzalo $^{15}$ proposed a cycle in which a pyroelectric is alternately connected to a heat source at $T_{2}$ and a heat sink at $T_{1}$, with the resulting current flowing through a load resistor (see Figure $3 b$ ). Gonzalo ${ }^{15}$ noted that the efficiency could be improved by cascading a series of materials with different Curie temperatures. 
Clingman and Moore ${ }^{16}$ described a circuit in which a pair of diodes controls the flow of current through a load (Figure $3 \mathrm{c})$ and a battery provides a bias field $\left(E_{1}\right.$ in Figure 3c). This variation on the resistive circuit does not drain current from the power supply through the load during the cooling half of the cycle.

Childress ${ }^{17}$ made some important modifications to the basic concept, using a switch to allow the capacitor to be connected to the load at strategic points in the thermal cycle (see Figure 3d). Starting at point 1, the switch is closed with the field $E_{1}$ across $C$. The switch is opened and the capacitor connected to a heat source, raising the temperature to $T_{2}$ at constant displacement. The permittivity is reduced as $T$ increases, so the field increases to $E_{\text {Max }}$ (point 2). The switch is closed and the capacitor discharges isothermally (point 3) delivering energy to the load. The switch is opened again, $C$ is connected to the heat sink so the temperature reduces to $T_{1}$, again at constant displacement and the field reduces to $E_{\mathrm{Min}}$ as the permittivity increases (point 4). Finally, the switch is closed and $C$ recharges through the load, delivering more energy to it and returning to point 1. The resulting cycle is analogous to the well-known Stirling cycle as it includes two steps at constant $D$ (constant entropy). Childress ${ }^{17}$ calculated that, for $\mathrm{BaTiO}_{3}$, with $T_{2} \approx 150^{\circ} \mathrm{C}$ and slightly higher than $T_{\mathrm{C}}\left(120^{\circ} \mathrm{C}\right)$, the converter has a maximum theoretical efficiency of ca $0.5 \%$, as compared with $\eta_{\text {Carnot }}=7.1 \%$. Childress also calculated that the power that could be extracted from such a device is $\sim 900 \mathrm{~W} \mathrm{~kg}^{-1}$ (considering only the mass of the dielectric), predicting from the thermal properties of the ceramic dielectric that the maximum frequency at which it could be cycled would be $\sim 16 \mathrm{~Hz}$. The work highlights a number of issues common to all cycles used for energy recovery and refrigeration:

- Problems are associated with alternately connecting the dielectric to a heat source and a heat sink and getting the heat into and out of the dielectric.

- The breakdown field of bulk dielectrics limits the performance that can be achieved.

Fatuzzo et al. ${ }^{18}$ examined various types of ferroelectric power converters and reached a conclusion similar to that of Childress, namely, that the efficiencies are low ( 0.5\%) and that the limiting factor is the fact that "the energy required to 
increase the temperature of the lattice is nearly always much larger than the energy required to destroy part of the polarization." Olsen et al. pointed out ${ }^{12}$ that the type of Stirling cycle illustrated in Figure $3 \mathrm{~d}$ requires the use of heat regeneration to minimize irreversible heat flows. This is an essential feature of all engines employing these cycles.

Olsen and co-workers ${ }^{19,20}$ published a series of studies in which they employed an electrical Ericsson cycle (Figure 3e). Starting at point $1_{\mathrm{a}}$, with field $E_{1}$ across $C$, connected to heat sink at $T_{1}, E$ is increased to $E_{2}$ moving from point $1_{\mathrm{a}}$ to point 2 via $1_{\mathrm{b}}$. (This assumes a field-induced ferroelectric phase transition between points $1_{\mathrm{a}}$ and $1_{\mathrm{b}}$.) At point $2, C$ is placed in contact with a heat source at $T_{2}$ so it moves to point 3 , where the field is reduced to $E_{1}$ returning $C$ to point 4 . They reduced the concept to practice using a modified lead zirconate titanate (PZT) ceramic $\left[\mathrm{Pb}_{0.99} \mathrm{Nb}_{0.02}\left(\mathrm{Zr}_{0.68} \mathrm{Sn}_{0.25} \mathrm{Ti}_{0.07}\right)_{0.98} \mathrm{O}_{3}, \mathrm{PNZST}\right]^{21}$ and compared the resistive, two-diode, Stirling, and Ericsson cycles with $T_{1}=170.2^{\circ} \mathrm{C}$ and $T_{2}=$ $157.9^{\circ} \mathrm{C}$ and a $2.8 \mathrm{MV} \mathrm{m}^{-1}$ upper field limit. The maximum output electrical energy densities for the various cycles were as follows: resistor, $2.2 \mathrm{~kJ} \mathrm{~m}^{-3} \mathrm{~K}^{-1}$; two-diode, $1.9 \mathrm{~kJ} \mathrm{~m}^{-3} \mathrm{~K}^{-1}$; Stirling, $5.6 \mathrm{~kJ} \mathrm{~m}^{-3} \mathrm{~K}^{-1}$; and Ericsson, $7.9 \mathrm{~kJ} \mathrm{~m}^{-3} \mathrm{~K}^{-1}$. Subsequently, Sebald et al. ${ }^{22}$ analyzed the cycles summarized in Figure 3 and derived materials figures of merit. For the resistive cycle, a coupling factor $\left(k^{2}\right)$ is given by

$$
k^{2}=\frac{p^{2} T_{\mathrm{h}}}{\varepsilon \varepsilon_{0} c^{\prime}},
$$

where $\varepsilon\|\| \|$ is the relative permittivity; $c^{\prime}$ is the volume specific heat, $c^{\prime}=C_{\mathrm{E}} \rho$; $\rho\|I\|$ is the material density; and $T_{\mathrm{h}}$ is the upper operating temperature. The conversion efficiency $\left(\eta_{\operatorname{Res}} \| I \mid\right)$ is given by

$$
\eta_{\text {Res }}=\frac{\pi}{4} k^{2} \eta_{\text {Carnot }}
$$

and the electrical energy extracted per cycle $\left(W_{\text {Cycle }}\right)$ is

$$
W_{\text {Cycle }}=\frac{\pi p^{2}}{4 \varepsilon}\left(T_{2}-T_{1}\right)^{2} .
$$


In the case of the Ericsson cycle, which is probably the most practical for energy harvesting, the materials become highly nonlinear in their behavior under the high fields, and the total electrical work can be expressed ${ }^{23}$ in terms of the electrocaloric work $Q_{\mathrm{ECE}}$ as follows:

$$
\begin{aligned}
& Q_{E C E}=T_{2} \int_{E_{1}}^{E_{2}} p d E \\
& W_{\text {Cycle }}=-\eta_{\text {Carnot }} Q_{E C E} \\
& \frac{\eta}{\eta_{\text {Carnot }}}=\frac{Q_{\mathrm{ECE}}}{c^{\prime}\left(T_{2}-T_{1}\right)+Q_{\mathrm{ECE}}}
\end{aligned}
$$

As a consequence, a material having a high electrocaloric activity will result in high pyroelectric energy-harvesting efficiency (ignoring system-level losses).

Table I lists the properties of several pyroelectric materials used either in a linear (zero- or low-field) regime with a resistive cycle or in a high applied field with an Ericsson cycle. The assumptions used in deriving the values in this table are that a $\pm 5^{\circ} \mathrm{C}$ sinusoidal temperature cycle is used, around the specified central temperature $T$. Several observations can be made from this table. First, if a simple linear resistive cycle is used, without applied bias field, the best material is a $0.72 \mathrm{PMN}-0.28 \mathrm{PT}$ (111)-oriented single crystal. However, the classic pyroelectric LTO, widely-used in infra-red sensors, also looks promising and with its high Curie temperature $\left(618^{\circ} \mathrm{C}\right)$, the potential exists for having a much wider temperature oscillation than the illustration given here. For example, assuming a central temperature of $300^{\circ} \mathrm{C}$ with a $\pm 100^{\circ} \mathrm{C}$ temperature cycle, the electrical energy recovered per cycle would be $3.5 \mathrm{MJ} \mathrm{m}^{-3}$, although the efficiency of the process would still be low ( $<1 \%$ of the Carnot efficiency). For the nonlinear materials exercised under the Ericsson cycle, the energy recovered is much higher than for the linear/resistive case, even with the small temperature oscillation assumed: $\sim 100 \mathrm{~kJ} \mathrm{~m}^{-3}$ for the ceramics and single-crystal materials, with 
efficiencies of 5-15\% of $\eta_{\text {Carnot. }}$ This is in agreement with Olsen et al.'s practical observations $^{21}$.

The electrical energy recovered rises to $\sim 1 \mathrm{MJ} \mathrm{m}^{-3}$, at $40-70 \%$ of $\eta_{\text {Carnot}}$, for the thin-film oxide and polymer materials. However, the thin-film materials achieve these high efficiencies only by virtue of very high applied electric fields (hundreds to thousands of megavolts per meter). Fields of this magnitude can only be sustained by perfect thin films and are well in excess of those that can be endured by bulk materials. This leads to a fundamental technological challenge: High energy recovery efficiency can be achieved by using very thin ferroelectric films under high electric fields, but a significant volume of the ferroelectric material needs to be used to deliver a useful amount of energy per cycle, which necessitates the stacking of many thin films.

It is worth noting that Sebald et al. ${ }^{23}$ reported the use of the Ericsson cycle with a $0.90 \mathrm{PMN}-0.10 \mathrm{PT}$ ceramic. They achieved a harvested energy of $186 \mathrm{~kJ} \mathrm{~m}^{-}$ ${ }^{3}$ for a $50 \mathrm{~K}$ temperature variation and an electric field cycle of $3.5 \mathrm{MV} \mathrm{m}^{-1}$, which is of the same order of magnitude as that achieved by Olsen et $\mathrm{al}^{21}$.

One can also compare the performance of pyroelectric energy harvesting with thermoelectric conversion efficiency over similar temperature ranges. ${ }^{37}$ For the best thermoelectrics based on $\mathrm{Bi}_{2} \mathrm{Te}_{3}$, with small temperature differences to maximize efficiency, $\eta$ reaches about $13 \%$ of $\eta_{\text {Carnot, }}$ which is inferior to the results for many of the potential pyroelectric systems under high fields. Of course, a fundamental difference between thermoelectric and pyroelectric energy harvesting is that the former requires a spatial temperature gradient, which is very commonly available, whereas the latter requires a temporal temperature oscillation at (typically) low frequencies to provide useful power levels. This is harder to accomplish and requires additional system complexity.

\section{Polymeric and ceramic ferroelectrics for electrocaloric cooling}

The preceding discussion was confined to the use of ferroelectrics in heat energy harvesting, but the Stirling and Ericsson cycles can, in principle, be used to extract heat by being run them in reverse. This offers the potential for solid- 
state refrigeration. The ECE has been known for many years, but the topic was given new impetus by the report in 2006 of a "giant" electrocaloric effect in a PZT95/05 thin film. ${ }^{33}$ Of course, materials exhibiting high $Q_{\text {ECE }}$ will also show good energy-recovery efficiencies.

The ECE in a dielectric is determined by the dipolar entropy change $\Delta S_{\mathrm{p}}$ between the polar and nonpolar states, that is,

$$
\Delta T=\frac{T}{C_{\mathrm{E}}}\left[S_{\mathrm{p}}(0, T)-S_{\mathrm{p}}(E, T)\right],
$$

where $S_{\mathrm{p}}(0, T)$ is the dipolar entropy when $E=0$ and $S_{\mathrm{p}}(E, T)$ corresponds to the entropy of a dipole-aligned state when an electric field $E$ is applied. Based on thermodynamic and statistical mechanics analyses, Pirc et al. ${ }^{38}$ derived the following expression for the potential temperature change:

$$
\Delta T_{\text {sat }}=\frac{T \ln \varphi}{3 \varepsilon_{0} \Theta C_{\mathrm{E}}} P_{\mathrm{S}}^{2} .
$$

In Equation $19, C_{\mathrm{E}}$ is the specific heat capacity, $\varphi$ is the number of possible polar states (entropy channels), $P_{\mathrm{S}}$ is the saturation polarization, and $\Theta$ is the Curie constant. Therefore, the development of polar dielectrics with both large $\varphi$ and small $\Theta$ is highly desirable, especially if $P_{\mathrm{S}}$ can be kept unchanged. In relaxor ferroelectrics, defect modification can lead to larger numbers of local states and, hence, can increase $\varphi$ compared to that of its normal ferroelectric counterpart. In ferroelectrics, $\Theta$ is directly related to the polar correlation length and the presence of random defect fields. In particular, relaxor ferroelectrics have much smaller polar regions than normal ferroelectrics. These considerations suggest that relaxor and highly disordered ferroelectrics might exhibit larger ECEs than normal ferroelectrics ${ }^{38}$.

Upon application of high-energy electron irradiation, the normal ferroelectric $\mathrm{P}(\mathrm{VDF}-\mathrm{TrFE})$ copolymer can be converted into a relaxor ferroelectric that displays a high dielectric constant ( 50 at $1 \mathrm{kHz})$, a large reversible polarization change, and high electrostriction at room temperature. ${ }^{39}$ Figure 4a presents the dielectric constant of a high-energy-electron-irradiated P(VDF-TrFE) 68/32 mol\% copolymer, which has a broad dielectric constant peak 
around room temperature and a peak position that moves progressively toward higher temperatures with increasing frequency, a characteristic feature of relaxor ferroelectrics. The high-energy electron irradiation breaks up the long-range polar correlation in the polymer, which stabilizes dipolar disordered states around room temperature and generates local polar states on the nanoscale that can enhance the ECE, as discussed earlier. The ECE of the irradiated P(VDF-TrFE) 68/32 mol\% copolymer measured near $33^{\circ} \mathrm{C}$ as a function of electric field is presented in Figure $4 \mathrm{~b} .{ }^{40}$ Under a field of $160 \mathrm{MV} \mathrm{m}^{-1}$, an adiabatic temperature change of $\Delta T$ $=20^{\circ} \mathrm{C}$ and an isothermal entropy change of $\Delta S=95 \mathrm{~J} \mathrm{~kg}^{-1} \mathrm{~K}^{-1}$ can be obtained.

A large ECE has also been observed for P(VDF-TrFE-CFE) relaxor ferroelectric polymers. The ECE of the P(VDF-TrFE-CFE) 59.2/33.6/7.2 mol\% terpolymer directly measured at $30^{\circ} \mathrm{C}$ is presented in Figure $4 \mathrm{c}$. It shows a very large temperature change of $\Delta T \approx 14^{\circ} \mathrm{C}$ induced under a $100 \mathrm{MV} \mathrm{m}^{-1}$ electric field. In addition to a large ECE, several relaxor ferroelectric polymers display an ECE that is nearly temperature independent, as presented in Figure $4 \mathrm{~d} .{ }^{41}$ For example, the P(VDF-TrFE-CFE) 59.2/33.6/7.2 mol\% relaxor ferroelectric terpolymer has an ECE response that is nearly temperature independent from $0^{\circ} \mathrm{C}$ to $45^{\circ} \mathrm{C}$, which is in sharp contrast to normal ferroelectrics, for which the ECE peaks at $T_{\mathrm{C}}$ and displays a strong temperature dependence.

Mischenko et al. ${ }^{33}$ first reported a temperature change of $12^{\circ} \mathrm{C}$ in a $350-\mathrm{nm}-$ thick $\mathrm{PbZr}_{0.95} \mathrm{Ti}_{0.05} \mathrm{O}_{3}$ thin film near its $T_{\mathrm{C}}\left(222^{\circ} \mathrm{C}\right)$. A temperature change of about $11^{\circ} \mathrm{C}$ was also observed in a 700-nm-thick $\mathrm{PbZrO}_{3}$ thin film near its $T_{\mathrm{C}}$ of $235^{\circ} \mathrm{C} .{ }^{42}$ However, the phase transitions in these thin films are first-order, and the $T_{\mathrm{C}}$ is too high for viable cooling applications near room temperature, although not for PE energy recovery applications. To obtain a large ECE over a wide range of temperatures near room temperature, La-doped lead PZT thin films were explored, and a value of $\Delta T|| I \mid \approx 40^{\circ} \mathrm{C}$ was reported under an electric field of $120 \mathrm{MV} \mathrm{m}^{-1}$ at $45^{\circ} \mathrm{C} .40$

A $\Delta T$ value of $9^{\circ} \mathrm{C}$ under an applied field of $72.3 \mathrm{MV} \mathrm{m}^{-1}$ in $0.93 \mathrm{PMN}-$ 0.07PT thin films was observed at the depolarizing temperature of $18^{\circ} \mathrm{C}$ compared to the dielectric constant peak at $35^{\circ} \mathrm{C}$, which suggests that a dipolar 
glass-relaxor phase transition occurs in this system. ${ }^{43}$ For $0.90 \mathrm{PMN}-0.10 \mathrm{PT}$, a maximum $\Delta \mathrm{T}$ of $5^{\circ} \mathrm{C}$ was observed at $75^{\circ} \mathrm{C}$, where a pseudocubic relaxor ferroelectric transforms into a cubic paraelectric phase. ${ }^{44} \mathrm{PMN}-\mathrm{PT}$ with $30-35 \%$ PT is extremely interesting, because the structural variations resulting from transitions about the morphotropic phase boundary can also contribute to the entropy and lead to an enhancement in the ECE. ${ }^{45-481}$ In many ferroelectrics, there exists more than one polar phase, and operation of the material near a tricritical point reduces the energy barriers for switching between different ferroelectric phases. ${ }^{49,50}$ Indeed, one of the reasons why the PZT95/05 composition ${ }^{33}$ might be so interesting is that it sits very close to a tricritical point in the ferroelectric, namely, the rhombohedral-to-paraelectric cubic phase transition in the high-Zrcontent PZT system. ${ }^{51}$ Indeed, any contribution to the entropy induced through the application of an electric field, whether this contribution is through electrical, magnetic, magnetoelectric, or structural order, should enhance the EC response. In particular, the thermodynamics of intrinsic multicaloric heating/cooling has been discussed in some detail. ${ }^{52}$ Furthermore, $\operatorname{Scott}^{53}$ has pointed-out that extrinsic effects due to domain wall motion cannot be ignored. Karthic and Martin ${ }^{76,77}$ have predicted that $\Delta T$ may be enhanced through reversible movements of ferroelectric domains. There is also experimental evidence that the clamping of domain wall motion by defects in $\mathrm{BaTiO}_{3}$ ceramic causes a reduction in $\Delta T{ }^{89}$

\section{Device and system considerations for materials selection and optimization}

The issues associated with the application of ferroelectric materials in real energy-harvesting or solid-state cooling systems bear a great deal of similarity and reflect similarly on the criteria for materials selection and the broad aspect of device/systems design. The basic figures of merit combining the pyroelectric, dielectric, and heat capacity describe which materials will be useful for a particular application and how they might be improved. A possible approach to decreasing the dielectric constant, for example, is to build-in a large internal bias field. In the case of PZT systems, this can be achieved by acceptor doping, which 
stabilizes the domain structure and produces double-loop-type behavior. ${ }^{54-562}$ Other ways of creating internal fields include building mesoscale composites, ${ }^{57}$ as well as multilayers and graded structures. ${ }^{58}$ For example, in a recent study, it was shown that the intrinsic PE and EC properties of PZT could be improved significantly by constructing $\mathrm{PZT} / \mathrm{SrTiO}_{3}$ heterostructures. ${ }^{59}$ Because the internal dc field clamps the polarizability, reductions in the dielectric constant by a factor of 10 or more are, in principle, possible. This internal field has the secondary effect of stabilizing the domain state and is thus also useful in making the material more robust to temperature excursions.

Careful consideration of the material from the perspective of the phase transition will lead to the selection of materials that are probably relaxor in character and that possibly sit near a tricritical point in the ferroelectric-toparaelectric transition. Clearly, the phase transition should be close to the required operating temperature. Therefore, for a heating, ventilating, and air conditioning (HVAC) system, a transition near or below room temperature might be desirable. On the other hand, active extraction of heat from an electronic junction, for example, might require $T_{\mathrm{C}}>100^{\circ} \mathrm{C}$. Harvesting energy from waste heat in an electronic system might require a similar $T_{\mathrm{C}}$ value, whereas harvesting energy from the human body (e.g., to power wearable electronics) requires $T_{\mathrm{C}} \approx 35^{\circ} \mathrm{C}$. Fortunately, with ferroelectric materials, one can choose from a wide range of transition temperatures (see Table I), and it is possible to tailor a suite of ferroelectric materials with cascading $T_{\mathrm{C}}$ values, optimizing the possibilities for energy extraction or cooling $\Delta T$ values.

Materials cascading is greatly assisted by the use of regeneration (Figure 5a). The particular example shown here is for a Stirling cycle. However, Carnot, Ericsson (two stages at constant E), Brayton, and hybrid cycles can also be used. He et al. ${ }^{60}$ concluded that the Stirling cycle is probably the best for use with a regenerator, coming closest to the performance of the reversible Carnot cycle, whereas the Ericsson cycle will experience a regenerative loss. Liquid ${ }^{20,61}$ and solid-state ${ }^{62}$ regenerators have been demonstrated for both energy harvesting and cooling. The ideal regenerating material should have a high thermal conductivity 
and a low thermal capacity. Considerable gains could be achieved by the use of sophisticated nanoscale composites designed to optimize these parameters.

An alternative to the use of a regenerator, which requires the pumping of liquids and the associated energy losses, is the use of a thermal diode or heat switch system. This would allow the EC element to be alternately connected with the heat source and the heat sink. Epstein and Molloy ${ }^{63}$ discussed the use of liquid crystals in this role, with the potential for including carbon nanotubes to increase thermal conductivity, whereas Ravindran et al. ${ }^{64}$ discussed the use of a microelectromechanical-system- (MEMS-) based thermal switch in the context of pyroelectric energy harvesting.

A key issue, which was recognized very early on, is the ability of the ferroelectric material to sustain a very high electric field of hundreds of megavolts per meter for an operational lifetime likely to require $\sim 10^{9}-10^{10}$ cycles. Such fields have been demonstrated for short periods, but it remains unclear whether the required lifetimes can be met. From Table I, one can see that, under ideal conditions, the best materials can harvest (or, conversely, pump) $\sim 100 \mathrm{~kJ} \mathrm{~m}^{-3}$ to 1 $\mathrm{MJ} \mathrm{m}{ }^{-3}$ of energy per cycle over a $10^{\circ} \mathrm{C}$ temperature range which implies that, to handle $1 \mathrm{~kW}$ of power working at $10 \mathrm{~Hz}$, one would need $\sim 10^{-3}$ to $10^{-4} \mathrm{~m}^{3}$ of material (or approximately a cube $10 \mathrm{~cm}$ on a side). This is not beyond the bounds of possibility, given the current state of both ceramic and polymer technologies, but it would require approximately 100,000 1- $\mu$ m-thick layers $\left(\mathrm{ca} .10 \mathrm{~cm}^{2}\right.$ ) and the use of multilayer assembly technologies, such as those used for multilayer ceramic capacitors (MLCs) or polymer capacitors (Figure 5b).

Kar-Narayan and Mathur ${ }^{65}$ demonstrated the ECE in a $\mathrm{BaTiO}_{3} \mathrm{MLC}$ and calculated its performance, ${ }^{66}$ predicting that an MLC array of about $0.6 \mathrm{~m}^{2}$ total area could provide up to $20 \mathrm{~kW}$ of cooling power. Epstein and Molloy ${ }^{63}$ also discussed the use of interleaved multilayer structures. The penetration of heat along the metal electrodes is key in determining how fast the system can be cycled, and the metal thermal diffusivity, $\alpha=K / c^{\prime}|| I \mid$ (where $K\|I\|$ is the thermal conductivity) is a key parameter. Crossley et al. ${ }^{67}$ modelled the EC performance of MLC structures, optimizing the operating frequency. The effects of metal 
thermal diffusivity were clear, with Ag electrodes $\left(\alpha=173 \times 10^{-6} \mathrm{~m}^{2} \mathrm{~s}^{-1}\right)$ performing much better than Ni electrodes $\left(\alpha=24.6 \times 10^{-6} \mathrm{~m}^{2} \mathrm{~s}^{-1}\right)$. They predicted that a given structure would be able to work roughly 5 times faster with $\mathrm{Ag}$ electrodes than with $\mathrm{Ni}$ electrodes, giving a much better power-handling capability. In mass terms, PVDF gives a better power handling capability (up to $\left.26 \mathrm{~kW} \mathrm{~kg}^{-1}\right)$ than PZT $\left(19 \mathrm{~kW} \mathrm{~kg}^{-1}\right)^{67}$ because of the former's lower density, although, in area terms, the performances were very similar (ca. $220 \mathrm{~kW} \mathrm{~m}^{-2}$ ). Ozbolt et al. ${ }^{68,69}$ discussed the practical implementation of electrocaloric cooling systems and concluded that the ECE offers a number of advantages over other solid-state cooling systems, such as magnetocalorics, including a wider temperature range of operation for a given material system.

Parasitic losses are a serious issue for electrothermal conversion devices. They diminish the coefficients of performance $(\mathrm{COP}=Q / W$, where $Q$ is the work performed and $W$ is the work supplied) of actual physical systems, often making commercial systems impractical as compared to state-of-the-art devices. This will be the case for all of the PE and ECE materials discussed thus far. Consequently, parasitic losses (see Figure 5c) must be identified and minimized in the design phase. Fortunately, such device- and system-level losses can be modeled by system-level integrators, allowing compensatory tradeoff assessments to be made. These models not only must tie together the electrothermal responses of the ECE or PE materials, but also must account for thermal transport losses normal to and along the working material, as well as those associated with the packaging and interconnects. In addition, mechanical robustness at the component or system level is strongly dependent on the induced mechanical stress/strains due to thermal gradients, mechanical loading, differences in thermal expansion, and piezoelectric deformation at high electric fields. Moreover, optimization for COP and mechanical robustness (e.g., mean time between failures, performance, cost, or a combination of these or other factors) needs to be done holistically as opposed to iteratively or sequentially. Comprehensive solutions are essential because the EC and PE material properties $(p, \varepsilon|| I||$, strain, dielectric breakdown strength, thermal conductivity, heat capacity, etc.) are functions of temperature, 
applied stress levels, imposed electric fields, and other properties. Indeed, changes often result as much from the way the materials are formed or packaged as from their intrinsic free space response.

In addition, many of the material parasitic losses, including losses due to electrical conduction, $\tan \delta\|I\|$, domain switching, and so on, can be minimized by appropriate materials engineering, guided by theoretical models. For example, tan $\delta\|I\|$ field and domain-switching losses can often be reduced by control of grain size and grain boundary composition, with strong guidance from both material and process models (Figure 5c).

There are multiple sources of dielectric loss in pyroelectric materials, and hence there are multiple factors that must be engineered to minimize the loss tangent for pyroelectric/electrocaloric applications. First, the electrical resistivity of the sample should be as high as possible, suggesting the use of materials with large bandgaps. This is particularly true when the material must be utilized at elevated temperatures, where thermal promotion of carriers is particularly problematic. Second, a major source of dielectric loss in ferroelectrics is associated with motion of domain walls across pinning sites in the material. It is not uncommon for the loss tangent to decrease by a factor of 5-10 when the material is heated through $T_{\mathrm{C}}$, as domain wall losses are eliminated in the paraelectric phase. Because the material must be used as a ferroelectric, however, this means that it is essential to engineer the material such that the domain wall concentration or mobility is reduced. The former can be achieved through use of appropriately oriented single crystals. Reductions in domain wall mobility, however, can be tailored by decreasing the grain size,${ }^{70,71}$ increasing the internal bias in the material,${ }^{72}$ mechanically clamping the film to an underlying substrate,${ }^{73}$ or modulating the defect chemistry of the ferroelectric material.

Finally, materials may be improved by increasing the electrical breakdown strength, that is, the strength of the electric field at which breakdown occurs. Many polymeric or oxide thin-film ferroelectrics have breakdown strengths that exceed those of polycrystalline ferroelectric ceramics by an order of magnitude. 
Recent advances in theoretical approaches and techniques will enable quantitative, predictive modeling to guide experimental work. The PE and ECE properties of ferroelectric thin films have been analyzed using the Landau theory of phase transformations taking into account the electrostatic and electromechanical boundary conditions, two-dimensional clamping of the substrate, the effect of structural domain formation, and the thermal stresses that develop as the films are cooled from the crystallization temperature. ${ }^{74-763}$ The electrocaloric properties of ferroelectrics and incipient ferroelectrics in thin-film form have been examined using similar tools that provide quantitative results to guide experimental work. ${ }^{10,11,77-79}$ Such predictive models, however, are limited to a few perovskite ferroelectrics, including $\mathrm{PbTiO}_{3}, \mathrm{BaTiO}_{3}, \mathrm{SrTiO}_{3}, \mathrm{~Pb}(\mathrm{Zr}, \mathrm{Ti}) \mathrm{O}_{3}$ (PZT), and (Ba,Sr) $\mathrm{TiO}_{3}(\mathrm{BST})$, for which dielectric stiffness, elastic, and electrostrictive coefficients have been determined experimentally. Theoretical approaches based on thermodynamic, electrostatic, and statistical mechanics considerations have been used to understand the adiabatic temperature changes in polar solids ${ }^{38}$ and asymmetric ferroelectric tunnel junctions, ${ }^{80}$ as well as pyroelectric response of ferroelectric nanowires. ${ }^{81}$ Although phase-field models have been developed for a number of materials systems that include ferroics and multiferroics, ${ }^{82}$ only limited studies have considered their application to understand correlations between microstructural features and electrothermal properties. ${ }^{83}$ In terms of atomistic approaches, there exist several methodologies based on first principles coupled with nonequilibrium molecular dynamics. These were developed to describe electrocaloric and pyroelectric responses in bulk and thin-film PZT, ${ }^{84} \mathrm{BST}^{85}{ }^{85} \mathrm{BaTiO}_{3},{ }^{86}$ and $\mathrm{LiNbO}_{3} .{ }^{87}$

The requirements for electrothermal applications present a significant challenge to the electroceramics and electronic polymers communities. There is a need for the development of comprehensive, multiscale theoretical tools in the search for better materials. This need is essentially at the core of the recent "Materials Genomics" initiatives ${ }^{88}$ that seek to accelerate materials discovery through the use of computations across length and time scales, supported by experimental work. Significant advances have been made in the theoretical 
understanding of strongly correlated systems at the electronic/atomic level. Still, the development of a new generation of ferroelectric materials for pyroelectric applications requires an integration of first-principles approaches with molecular dynamics, phase-field, and continuum-level formalisms to address the roles of electronic, atomic, microstructural, and device-level features. We believe that such a multiscale computational materials methodology, combined with judicious experimental work, would allow engineers to overcome the limitations discussed above.

\section{Summary}

This article has laid out the current state of the art for the use of ferroelectric materials in the interconversion of thermal and electrical energy. The past eight years have seen remarkable progress in the development of ferroelectric materials for both pyroelectric energy harvesting and electrocaloric cooling, especially in thin-film relaxor oxides and polymers, to the point where practical applications are starting to appear feasible, with the promise of significantly higher efficiencies than can be achieved with other solid-state technologies. There is clear promise for further performance improvements through the development of new ferroelectric relaxor compositions.

Real challenges remain to be addressed, however, especially the demonstration of adequate reliability and lifetimes in ferroelectric materials under the high electric fields necessary to realize the promised efficiencies. This will allow large numbers of ferroelectric thin films to be assembled in a form where they can be used with thermal regenerators at low cost. It has also been shown that other materials developments can potentially help in the exploitation of this new technology. These include low-cost, high-thermal-conductivity electrodes to use with the ferroelectric elements and new types of regenerator systems that combine high thermal conductivity with low specific heat. The development of low-cost thermal switch technologies might also have a role to play in bringing this exciting new technology through to full realization.

\section{Acknowledgments}


The authors express their thanks to the many individuals who helped support this article. J.V.M. is particularly indebted to T. Radcliff and S. Annapragada at UTRC for critical systems-level discussions. R.W.W. thanks N. Mathur (University of Cambridge, UK) for helpful discussions.

\section{References}

1. S.B. Lang, Ferroelectrics 230, 401 (1999).

2. R.W. Whatmore, Rep. Prog. Phys. 49, 1335 (1986).

3. P. Muralt, Rep. Prog. Phys. 64, 1339 (2001).

4. D. Guyomar, S. Pruvost, G. Sebald, IEEE Trans. Ultrason. Ferroelectr. Freq. Control 55, 279 (2008).

5. X. Moya, S. Kar-Narayan, N.D. Mathur, Nat. Mater. 13, 439 (2014).

6. J.F. Scott, NPG Asia Mater. 5, e72 (2013).

7. M.E. Lines, A.M. Glass, Principles and Applications of Ferroelectrics and Related Materials (Oxford University Press, Oxford, UK, 1977).

8. A.M. Glass, Phys. Rev. 172, 564 (1968).

9. Y. Furukawa, K. Kitamura, E. Suzuki, K. Niwa, J. Cryst. Growth 197, 889 (1999).

10. G. Akcay, S.P. Alpay, G.A. Rossetti, J.F. Scott, J. Appl. Phys. 103, (2008).

11. J. Zhang, A.A. Heitmann, S.P. Alpay, G.A. Rossetti Jr., J. Mater. Sci. 44, 5263 (2009).

12. R.B. Olsen, D.A. Bruno, J.M. Briscoe, J. Appl. Phys. 58, 4709 (1985).

13. D.G. Frood, Can. J. Phys. 32, 313 (1954).

14. A. van der Ziel, J. Appl. Phys. 45, 4128 (1974).

15. J.A. Gonzalo, Ferroelectrics 11, 423 (1976).

16. W.H. Clingman, R.G. Moore, J. Appl. Phys. 32, 675 (1961).

17. J.D. Childress, J. Appl. Phys. 33, 1793 (1962).

18. E. Fatuzzo, H. Kiess, R. Nitsche, J. Appl. Phys. 37, 510 (1966). 
19. R.B. Olsen, J.M. Briscoe, D.A. Bruno, W.F. Butler, Ferroelectrics 38, 975 (1981).

20. R.B. Olsen, J. Energy 6, 91 (1982).

21. R.B. Olsen, D. Evans, J. Appl. Phys. 54, 5941 (1983).

22. G. Sebald, E. Lefeuvre, D. Guyomar, IEEE Trans. Ultrason. Ferroelectr.

Freq. Control 55, 538 (2008).

23. G. Sebald, S. Pruvost, D. Guyomar, Smart Mater. Struct. 17, 015012 (2008).

24. H.P. Beerman, Infrared Phys. 15, 225 (1975).

25. M. Davis, D. Damjanovic, N. Setter, J. Appl. Phys. 96, 2811 (2004).

26. R.W. Whatmore, F.W. Ainger, Proc. SPIE 395, 261 (1983).

27. Q. Zhang, R.W. Whatmore, J. Appl. Phys. 94, 5228 (2003).

28. H. Sussner, D.E. Horne, D.Y. Yoon, Appl. Phys. Lett. 32, 137 (1978).

29. A. Navid, C.S. Lynch, L. Pilon, Smart Mater. Struct. 19, 055006 (2010).

30. L. Shebanov, K. Borman, Ferroelectrics 127, 143 (1992).

31. G. Sebald, L. Seveyrat, D. Guyomar, L. Lebrun, B. Guiffard, S. Pruvost, J. Appl. Phys. 100, 124112 (2006).

32. A.S. Mischenko, Q. Zhang, R.W. Whatmore, J.F. Scott, N.D. Mathur, Appl. Phys. Lett. 89, 242912 (2006).

33. A.S. Mischenko, Q. Zhang, J.F. Scott, R.W. Whatmore, N.D. Mathur, Science 311, 1270 (2006).

34. B. Neese, B.J. Chu, S.G. Lu, Y. Wang, E. Furman, Q.M. Zhang, Science 321, 821 (2008).

35. E. Defay, S. Crossley, S. Kar-Narayan, X. Moya, N.D. Mathur, Adv. Mater. 25, 3337 (2013).

36. P.F. Liu, J.L. Wang, X.J. Meng, J. Yang, B. Dkhil, J.H. Chu, New J. Phys. 12, 023035 (2010).

37. G. Min, D.M. Rowe, K. Kontostavlakis, J. Phys. D: Appl. Phys. 37, 1301 (2004).

38. R. Pirc, Z. Kutnjak, R. Blinc, Q.M. Zhang, Appl. Phys. Lett. 98, 021909 (2011). 
39. Q.M. Zhang, V. Bharti, X. Zhao, Science 280, 2101 (1998).

40. S.G. Lu, B. Rozic, Q.M. Zhang, Z. Kutnjak, X.Y. Li, E. Furman, L.J. Gorny, M.R. Lin, B. Malic, M. Kosec, R. Blinc, R. Pirc, Appl. Phys. Lett. 97, 162904 (2010).

41. X.Y. Li, X.S. Qian, S.G. Lu, J.P. Cheng, Z. Fang, Q.M. Zhang, Appl. Phys. Lett. 99, 052907 (2011).

42. J. Parui, S.B. Krupanidhi, Phys. Status Solidi RRL 2, 230 (2008).

43. T.M. Correia, J.S. Young, R.W. Whatmore, J.F. Scott, N.D. Mathur, Q. Zhang, Appl. Phys. Lett. 95, 182904 (2009).

44. A.S. Mischenko, Q. Zhang, R.W. Whatmore, J.F. Scott, N.D. Mathur, Appl. Phys. Lett. 89, 242912 (2006).

45. Z.Y. Feng, D.Q. Shi, R. Zeng, S.X. Dou, Thin Solid Films 519, 5433 (2011).

46. Z.Y. Feng, D.Q. Shi, S.X. Dou, Solid State Commun. 151, 123 (2011).

47. D. Saranya, A.R. Chaudhuri, J. Parui, S.B. Krupanidhi, Bull. Mater. Sci. 32, 259 (2009).

48. Y. He, X.M. Li, X.D. Gao, X. Leng, W. Wang, Funct. Mater. Lett. 4, 45 (2011).

49. B. Rozic, M. Kosec, H. Ursic, J. Holc, B. Malic, Q.M. Zhang, R. Blinc, R. Pirc, Z. Kutnjak, J. Appl. Phys. 110, 064118 (2011).

50. Z.K. Liu, X.Y. Li, Q.M. Zhang, Appl. Phys. Lett. 101, 082904 (2012).

51. R.W. Whatmore, R. Clarke, A.M. Glazer, J. Phys. C: Solid State Phys. 11, 3089 (1978).

52. M.M. Vopson, Solid State Commun. 152, 2067 (2012).

53. J.F. Scott, Annu. Rev. Mater. Res. 41, 229 (2011).

54. G.H. Jonker, J. Am. Ceram. Soc. 55, 57 (1972).

55. K. Carl, K.H. Hardtl, Ferroelectrics 17, 473 (1977).

56. J. Ricote, R.W. Whatmore, D.J. Barber, J. Phys.: Condens. Matter 12, 323 (2000).

57. K. Zhou, S.A. Boggs, R. Ramprasad, M. Aindow, C. Erkey, S.P. Alpay, Appl. Phys. Lett. 93, 102908 (2008). 
58. N.W. Schubring, J.V. Mantese, A.L. Micheli, A.B. Catalan, R.J. Lopez, Phys. Rev. Lett. 68, 1778 (1992).

59. M. Kesim, J. Zhang, S. Alpay, L. Martin, Appl. Phys. Lett. 105, 052901 (2014).

60. J.H. He, J.C. Chen, Y.H. Zhou, J.T. Wang, Energy Convers. Manage. 43, 2319 (2002).

61. Y.V. Sinyavsky, V.M. Brodyansky, Ferroelectrics 131, 321 (1992).

62. H.M. Gu, X.S. Qian, X.Y. Li, B. Craven, W.Y. Zhu, A.L. Cheng, S.C. Yao, Q.M. Zhang, Appl. Phys. Lett. 102, 122904 (2013).

63. R.I. Epstein, K.J. Malloy, J. Appl. Phys. 106, 064509 (2009).

64. S.K.T. Ravindran, T. Huesgen, M. Kroener, P. Woias, Appl. Phys. Lett. 99, $104102(2011)$.

65. S. Kar-Narayan, N.D. Mathur, Appl. Phys. Lett. 95, 242903 (2009).

66. S. Kar-Narayan, N.D. Mathur, J. Phys. D: Appl. Phys. 43, 032002 (2010).

67. S. Crossley, J.R. McGinnigle, S. Kar-Narayan, N.D. Mathur, Appl. Phys. Lett. 104, 082909 (2014).

68. M. Ozbolt, A. Kitanovski, J. Tusek, A. Poredos, Int. J. Refrig. 37, 16 (2014).

69. M. Ozbolt, A. Kitanovski, J. Tusek, A. Poredos, Int. J. Refrig. 40, 174 (2014).

70. C.A. Randall, N. Kim, J.P. Kucera, W.W. Cao, T.R. Shrout, J. Am. Ceram. Soc. 8, 677 (1998).

71. F. Griggio, S. Trolier-McKinstry, J. Appl. Phys. 107, 024105 (2010).

72. N. Bassiri-Gharb, I. Fujii, E. Hong, S. Trolier-McKinstry, D.V. Taylor, D. Damjanovic, J. Electroceram. 19, 47 (2007).

73. F. Griggio, S. Jesse, A. Kumar, O. Ovchinnikov, H. Kim, T.N. Jackson, D. Damjanovic, S.V. Kalinin, S. Trolier-McKinstry, Phys. Rev. Lett. 108, (2012).

74. J. Zhang, M.W. Cole, S.P. Alpay, J. Appl. Phys. 108, (2010).

75. M.T. Kesim, J. Zhang, S. Trolier-McKinstry, J.V. Mantese, R.W. Whatmore, S.P. Alpay, J. Appl. Phys. 114, 157604 (2013).

76. J. Karthik, L.W. Martin, Phys. Rev. B: Condens. Matter 84, 024102 (2011).

77. J. Karthik, L.W. Martin, Appl. Phys. Lett. 99, 032904 (2011). 
78. J. Zhang, I.B. Misirlioglu, S.P. Alpay, G.A. Rossetti, Appl. Phys. Lett. 100, 222909 (2012).

79. Y.P. Shi, A.K. Soh, Acta Mater. 59, 5574 (2011).

80. Y. Liu, I.C. Infante, X.J. Lou, B. Dkhil, Appl. Phys. Lett. 104, 082901 (2014).

81. A.N. Morozovska, E.A. Eliseev, G.S. Svechnikov, S.V. Kalinin, J. Appl. Phys. 108, 042009 (2010).

82. L.-Q. Chen, Annu. Rev. Mater. Res. 32, 113 (2002).

83. B. Li, J.B. Wang, X.L. Zhong, F. Wang, Y.C. Zhou, J. Appl. Phys. 107, 014109 (2010).

84. S. Prosandeev, I. Ponomareva, L. Bellaiche, Phys. Rev. B: Condens. Matter 78, 052103 (2008).

85. I. Ponomareva, S. Lisenkov, Phys. Rev. Lett. 108, 167604 (2012).

86. M. Marathe, C. Ederer, Appl. Phys. Lett. 104, 212902 (2014).

87. Q. Peng, R.E. Cohen, Phys. Rev. B: Condens. Matter 83, 220103 (2011).

88. Integrated Computational Materials Engineering: A Transformational Discipline for Improved Competitiveness and National Security (The National Academies Press, Washington, DC, 2008).

89. Y. Bai, X. Han, X. C. Zheng, L. J. Qiao, Sci. Rep. 3, 2895 (2013). 


\begin{tabular}{|c|c|c|c|c|c|c|c|c|c|}
\hline \multicolumn{10}{|c|}{ Linear Materials Employed in a Resistive Cycle } \\
\hline Material $^{\mathrm{b}}$ & Type $^{\mathrm{c}}$ & $\begin{array}{c}p \\
\left(\mu \mathrm{C} \mathbf{m}^{-2} \mathbf{K}^{-1}\right)\end{array}$ & $\varepsilon$ & $\begin{array}{c}c^{\prime} \\
\left(\mathbf{M J} \mathbf{m}^{-3} \mathbf{K}^{-1}\right)\end{array}$ & $\begin{array}{l}T \\
{ }^{\circ} \mathbf{C}\end{array}$ & $\begin{array}{c}W_{\text {cycle }} \\
\left(\mathbf{k J ~ m}^{-3}\right)\end{array}$ & $\eta_{\text {Carnot }}$ & $\eta_{\text {Res }} / \eta_{\text {Carnot }}$ & $\operatorname{Ref}(\mathbf{s})$ \\
\hline $\mathrm{LiTaO}_{3}$ & $\mathrm{X}$ & 230 & 54 & 3.2 & 100 & 8.7 & $2.6 \%$ & $0.81 \%$ & 8,24 \\
\hline $0.72 \mathrm{PMN}-0.28 \mathrm{PT}$ & $\begin{array}{c}\mathrm{X} \\
(111) \\
\end{array}$ & 1071 & 660 & 2.5 & 75 & 15.4 & $2.8 \%$ & $1.85 \%$ & 25 \\
\hline PZFNTU & $\mathrm{C}$ & 380 & 290 & 2.5 & 100 & 4.4 & $2.6 \%$ & $0.53 \%$ & 26 \\
\hline PZT30/70-0.01Mn & $\mathrm{F}$ & 300 & 380 & 2.5 & 100 & 2.1 & $2.6 \%$ & $0.25 \%$ & 27 \\
\hline PVDF & $\mathrm{P}$ & 30 & 11 & 2.5 & 37 & 0.7 & $3.2 \%$ & $0.09 \%$ & 28 \\
\hline PVDF-TrFE 60/40 & $\mathrm{P}$ & 45 & 29 & 2.3 & 77 & 0.6 & $2.8 \%$ & $0.08 \%$ & 29 \\
\hline \multicolumn{10}{|c|}{ Nonlinear Materials Employed in Ericsson Cycle } \\
\hline Material $^{\mathbf{b}}$ & Type $^{\text {c }}$ & $\underset{\left(\mathbf{M J} \mathbf{m}^{-3}\right)}{Q_{\text {ECE }}}$ & $\begin{array}{c}E_{1} \\
\left(\mathbf{M V ~ ~ m ^ { - 1 }}\right) \\
\end{array}$ & $\begin{array}{c}c^{\prime} \\
\left(\mathbf{M J} \mathbf{m}^{-3} \mathbf{K}^{-1}\right)\end{array}$ & $\begin{array}{l}T \\
{ }^{\circ} \mathbf{C}\end{array}$ & $\begin{array}{c}W_{\text {cycle }} \\
\left(\mathbf{k J ~ m}^{-3}\right)\end{array}$ & $\eta$ Carnot & $\eta_{\text {Res }} / \eta_{\text {Carnot }}$ & $\operatorname{Ref}(\mathbf{s})$ \\
\hline 0.95PST-0.05PSS & $\mathrm{C}$ & 4.2 & 2.5 & 2.5 & -5 & 154 & $3.7 \%$ & $14 \%$ & 30 \\
\hline $0.90 \mathrm{PMN}-0.1 \mathrm{PT}$ & $\mathrm{C}$ & 1.4 & 3.5 & 2.5 & 30 & 45 & $3.2 \%$ & $5 \%$ & 23 \\
\hline $0.75 \mathrm{PMN}-0.25 \mathrm{PT}$ & $\begin{array}{c}\mathrm{X} \\
(111)\end{array}$ & 3.2 & 2.5 & 2.5 & 75 & 91 & $2.8 \%$ & $11 \%$ & 31 \\
\hline $0.75 \mathrm{PMN}-0.25 \mathrm{PT}$ & $\mathrm{F}$ & 15 & 90 & 2.5 & 100 & 397 & $2.6 \%$ & $38 \%$ & 32 \\
\hline PZT95/05 & $\mathrm{F}$ & 31 & 78 & 2.5 & 220 & 631 & $2.0 \%$ & $56 \%$ & 33 \\
\hline PVDF-TrFE 55-45 & $\mathrm{P}$ & 38 & 200 & 2.3 & 37 & 1206 & $3.2 \%$ & $62 \%$ & 34,35 \\
\hline PVDF-TrFE-CFE & $\mathrm{P}$ & 61 & 350 & 2.3 & 77 & 1718 & $2.8 \%$ & $73 \%$ & 35,36 \\
\hline
\end{tabular}

Table I. Properties of several pyroelectric materials when used for thermal energy harvesting in either a resistive (linear) or Ericsson cycle. ${ }^{a}$ Computed parameters assume a temperature cycle of $\pm 5^{\circ} \mathrm{C}$ about $T$. ${ }^{b}$ Material codes defined in text, with the following exceptions: $\mathrm{PST}=\mathrm{PbSc}_{1 / 2} \mathrm{Ta}_{1 / 2} \mathrm{O}_{3} ; \mathrm{PSS}=\mathrm{PbSc}_{1 / 2} \mathrm{Sb}_{1 / 2} \mathrm{O}_{3} ; \mathrm{PZFNTU}=\mathrm{Pb}\left(\mathrm{Zr}_{0.58} \mathrm{Fe}_{0.2} \mathrm{Nb}_{0.2} \mathrm{Ti}_{0.02}\right)_{0.995} \mathrm{U}_{0.005} \mathrm{O}_{3} ; \mathrm{PZT}_{2} / 1-x=\mathrm{PbZr}_{x} \mathrm{Ti}_{1-x} \mathrm{O}_{3}$, where $0.01 \mathrm{Mn}$ means doped with $1 \% \mathrm{Mn}$. ${ }^{\circ}$ Types: $\mathrm{C}=$ ceramic, $\mathrm{X}=$ single crystal, $\mathrm{F}=$ thin oxide film, $\mathrm{P}=$ thin polymer film. 
Figures

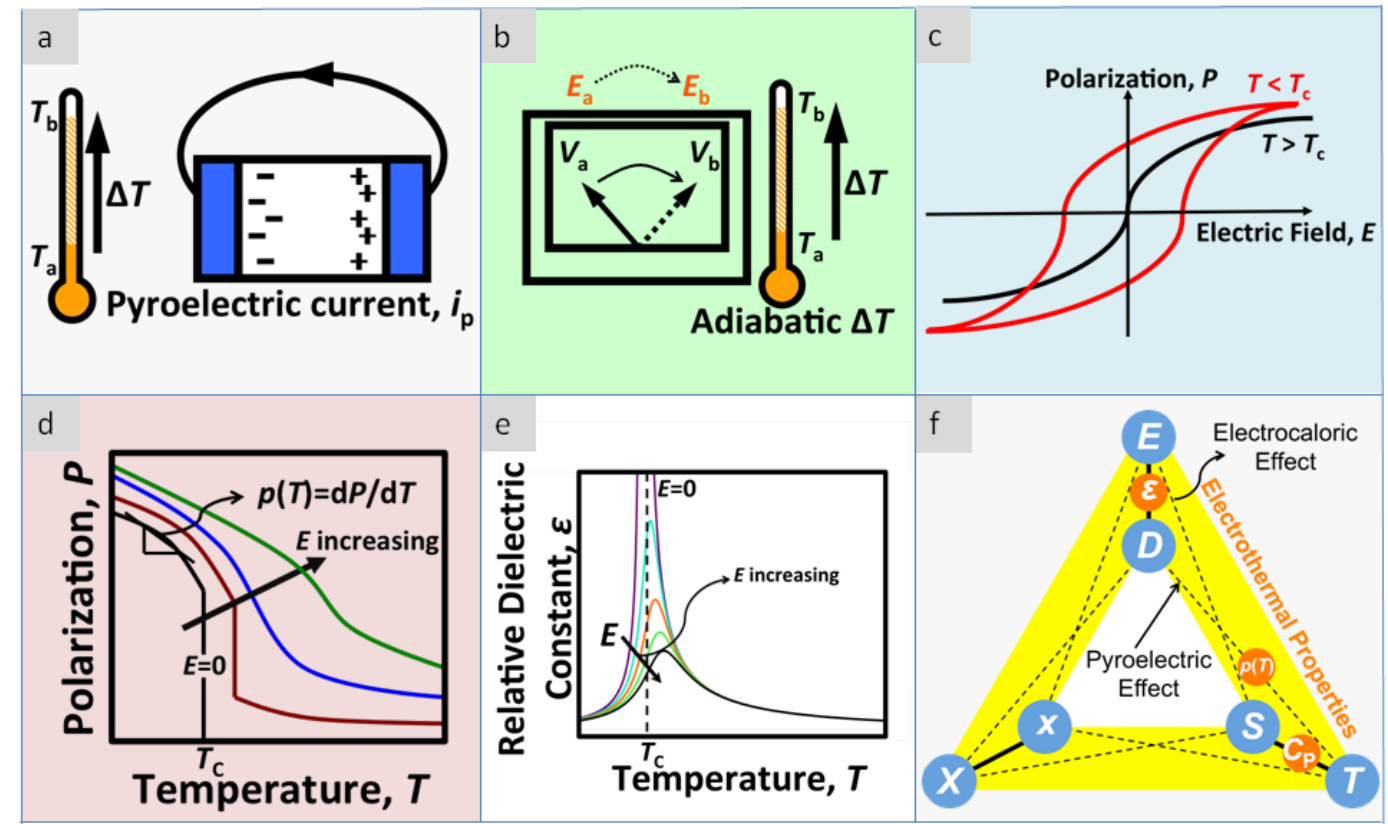

Figure 1. (a) Pyroelectric effect: A change in temperature results in a variation in the polarization that generates a pyroelectric current. (b) Electrocaloric effect: A change in applied electric potential from $V_{\mathrm{a}}$ to $V_{\mathrm{b}}$ generates an electric field change $\Delta E$ that results in an adiabatic temperature variation $\Delta T$. (c) Polarization $(P)$-applied electric field $(E)$ responses of a ferroelectric material above and below the Curie temperature, $T_{\mathrm{C}}$. Below $T_{\mathrm{C}}$, there is a hysteretic behavior associated with the nucleation and growth of electrical domains. (d) Variation of polarization with respect to an applied electric field $E$ for a ferroelectric. The electric field destroys the phase transformation at $T_{\mathrm{C}}$. (e) Change in the relative dielectric constant $\varepsilon_{\mathrm{R}}$ as a function of $E$. The lambda-type anomaly at $T_{\mathrm{C}}$ is smeared upon application of the electric field. (f) Heckmann diagram correlating applied stress $\sigma$, applied electric field $E$, and temperature $T$ in a ferroelectric material. $D, S, \varepsilon, \varepsilon_{\mathrm{R}}, p$, and $C_{\mathrm{p}}$ are the dielectric displacement, entropy, strain, relative dielectric constant, pyroelectric coefficient, and heat capacity at constant pressure, respectively. 


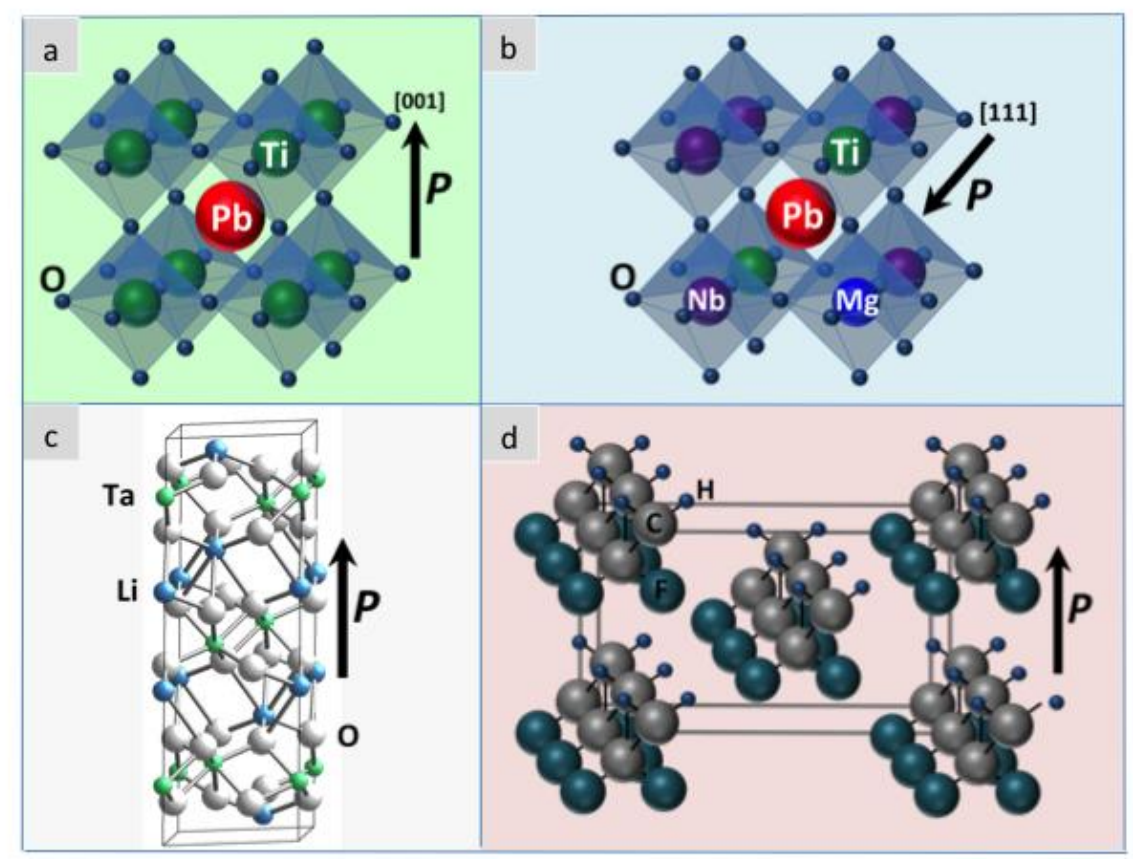

Figure 2. Crystal structures of the four most common pyroelectric materials: (a) $\mathrm{PbTiO}_{3}$; (b) $x \mathrm{~Pb}\left(\mathrm{Mg}_{1 / 3} \mathrm{Nb}_{2 / 3}\right) \mathrm{O}_{3}-(1-x) \mathrm{PbTiO}_{3}(\mathrm{PMN}-\mathrm{PT})$ in the rhombohedral phase; (c) $\mathrm{LiTaO}_{3}$; and (d) poly(vinylidene difluoride) (PVDF), $-\left(\mathrm{C}_{2} \mathrm{H}_{2} \mathrm{~F}_{2}\right)_{n}-$. The direction of spontaneous polarization is also shown. 

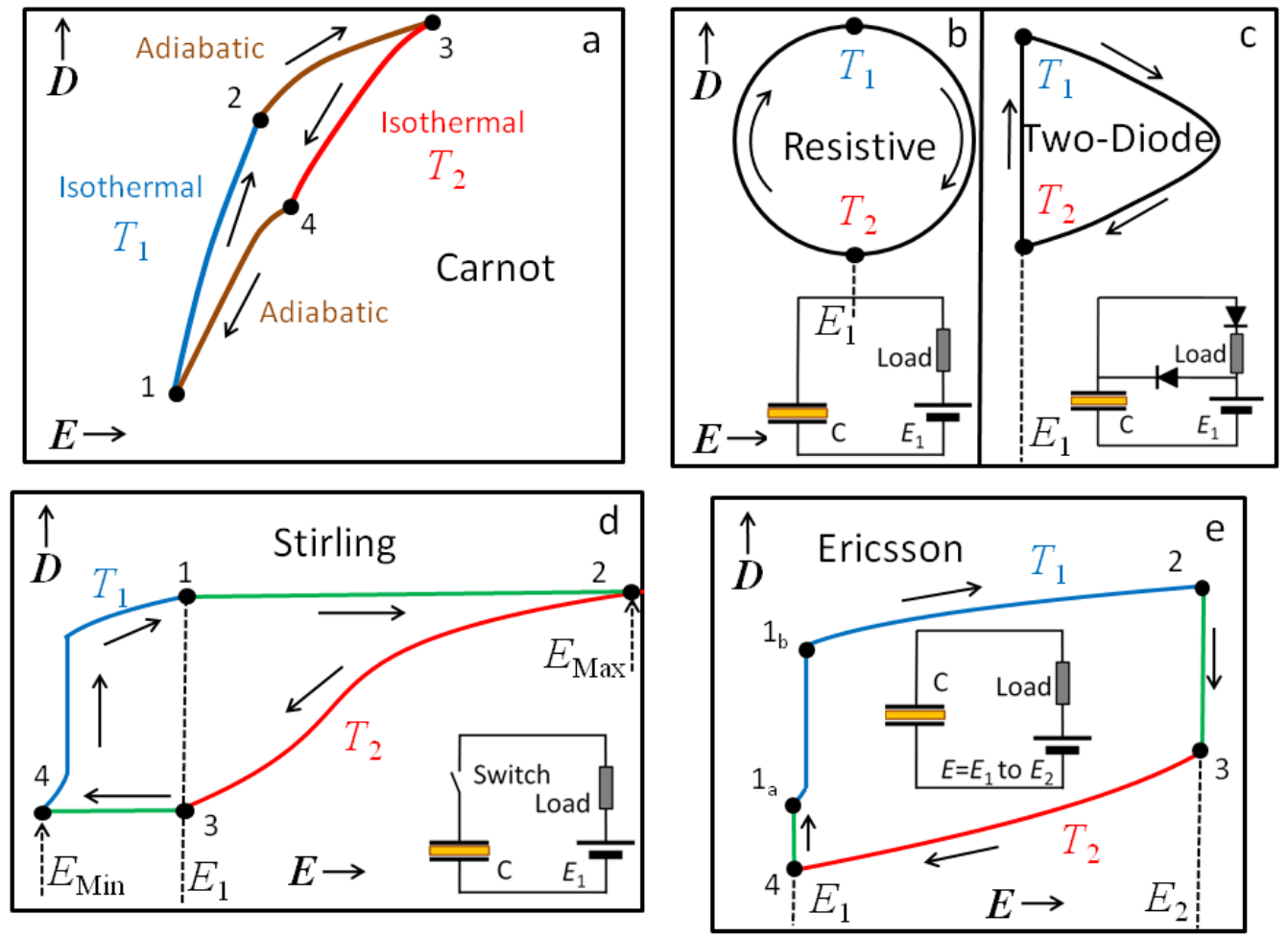

Figure 3. The principal thermodynamic cycles which have been used in pyroelectric energy recovery and harvesting, and simple circuit schematics which can be used to implement them. The capacitor $(\mathrm{C})$ is the active ferroelectric element and the battery represents a DC power supply providing the bias field. In each cycle we start at point 1 and move around to point 4 . In each case $C$ is cycled between two temperatures $T_{1}$ and $T_{2}$, with $T_{1}<T_{2}$. The cycles illustrated are a) Carnot b) Resistive c) Two-Diode d) Stirling e) Ericsson. 

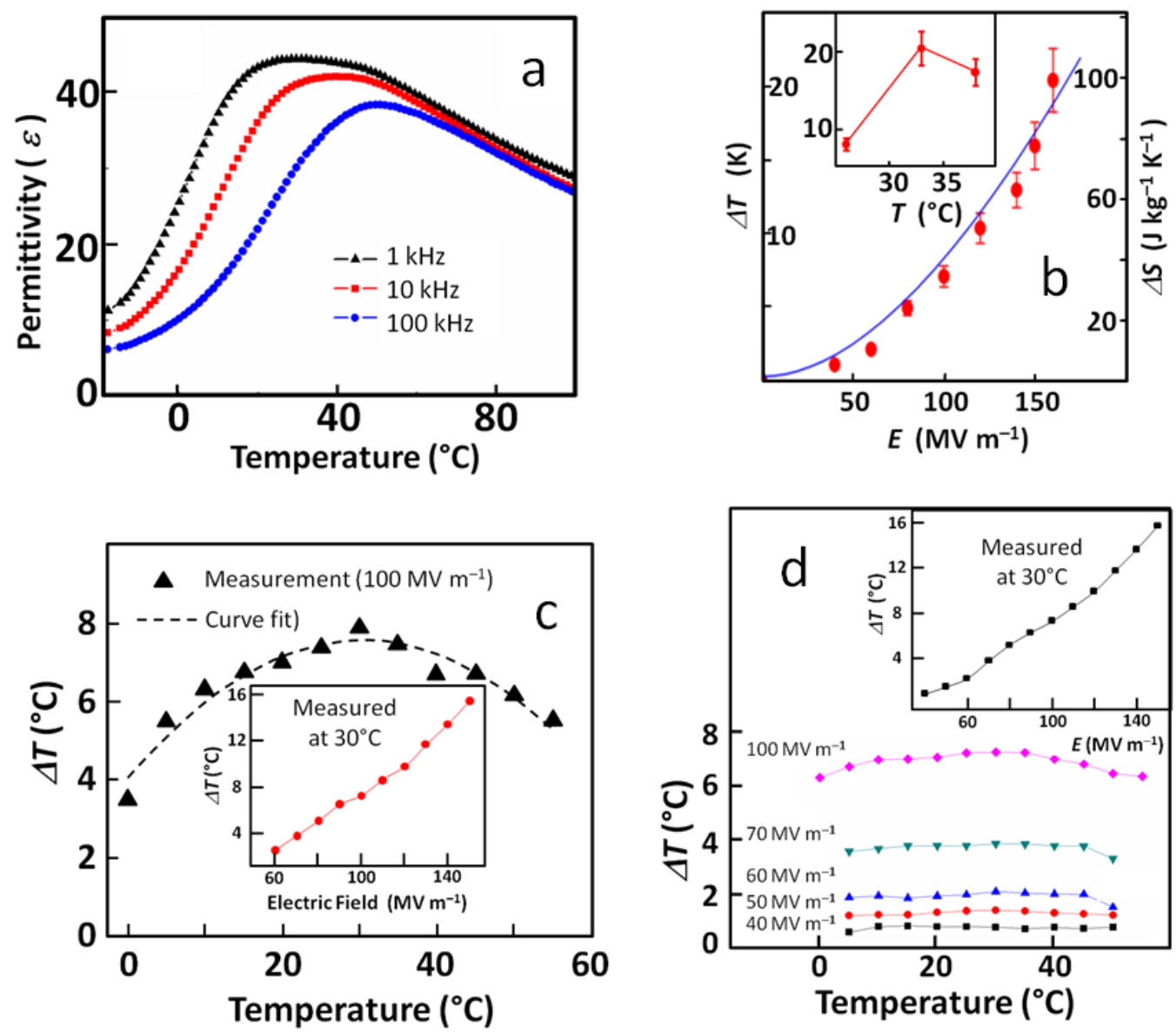

Figure 4. Electrocaloric properties of various ferroelectric copolymer systems: (a) Dielectric constant versus temperature measured at different frequencies and (b) directly measured ECE for a high-energy-electron-irradiated P(VDF-TrFE) 68/32 mol\% relaxor copolymer. ${ }^{40}$ (c) Adiabatic temperature change as a function of sample temperature in stretched $\mathrm{P}(\mathrm{VDF}-\mathrm{TrFE}-\mathrm{CFE})$ terpolymer under a constant electric field of $100 \mathrm{MV} \mathrm{m}^{-1}$. Inset: Adiabatic temperature change as a function of applied electric field measured at $30^{\circ} \mathrm{C}$. (d) Adiabatic temperature change as a function of sample temperature in unstretched P(VDF-TrFE-CFE) 59.2/33.6/7.2 mol\% terpolymer under different constant electric fields of $50-100 \mathrm{MV} \mathrm{m}^{-1}$. Inset: Adiabatic temperature change as a function of applied electric field, also measured at $30^{\circ} \mathrm{C} .^{41}$ 

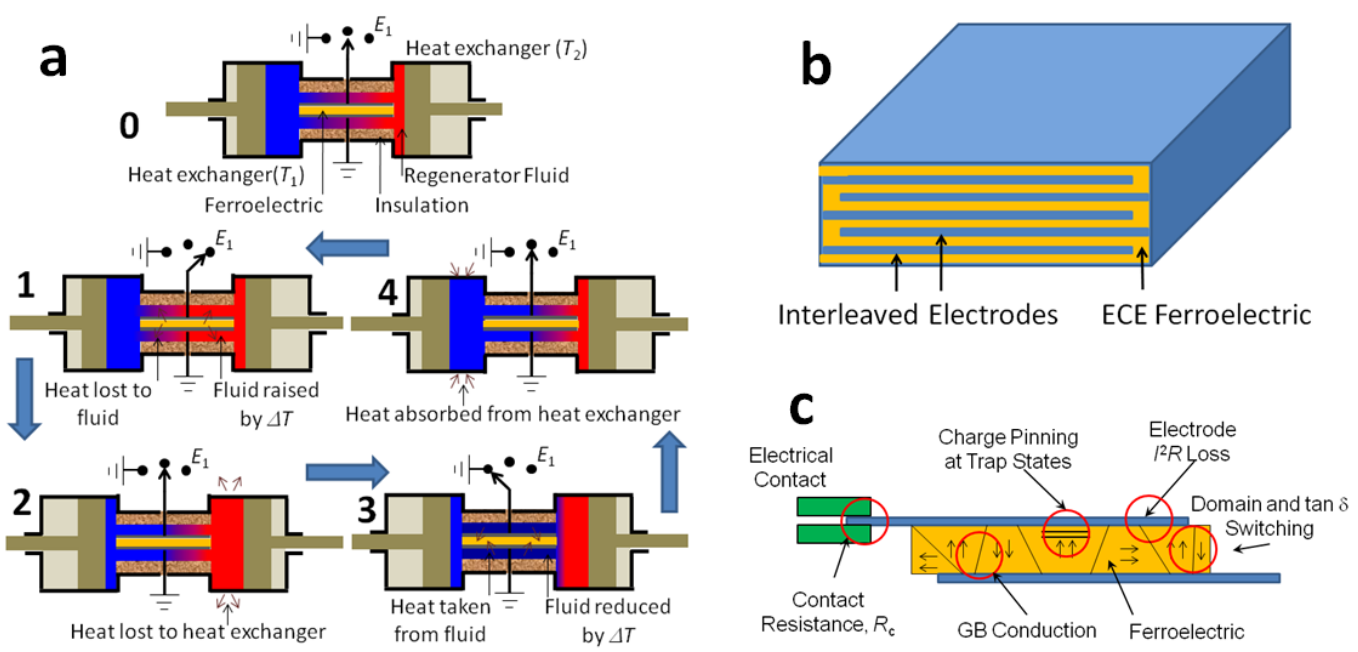

Figure 5. (a) Schematic of a solid-state refrigeration system operating in a regenerative fashion. The system (see diagram 0 ) employs a fluid regenerator that is pumped between two heat exchangers held at $T_{1}$ and $T_{2}\left(T_{1}<T_{2}\right)$. The fluid flows past the ferroelectric element in an insulated region, so that all the heat exchange is between the fluid and the EC element. (1) A field $E_{1}$ is applied to the EC element, and the heat from the EC element is released into the fluid. (2) The field is disconnected, and the fluid is pumped past the EC element so that the excess heat is lost at $T_{2}$. As the EC element is electrically floating, this occurs at constant electrical displacement. (3) The EC element is shorted so that the field returns to zero, cooling the fluid. (4) The EC element is again put to open circuit, and the fluid is pumped back into the heat exchanger at $T_{1}$, so that the fluid then absorbs heat from the heat exchanger. The cycle then repeats. (b) Schematic diagram of an MLCC structure. (c) Examples of potential sources of parasitic losses that must be taken into account in an actual device. Parasitic losses at the material and device levels are especially insidious, and care must be taken to minimize their impacts on the overall coefficient of performance. 


\section{Author biographies}

S. Pamir Alpay is a professor of materials science and engineering at the University of Connecticut (UConn). He holds a joint appointment with the Department of Physics and is affiliated with UConn's Institute of Materials Science. His main research interests are in the area of modeling phase transformations in functional materials with a particular emphasis on dielectric and electrothermal applications. He is a Fellow of the American Physical Society and a member of the American Ceramics Society and the

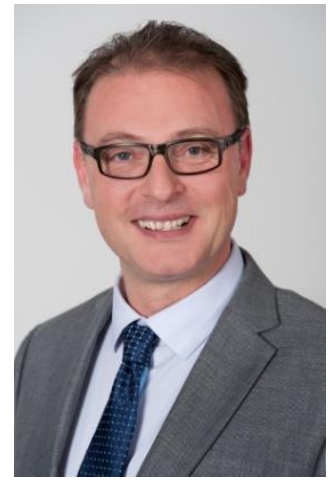
Materials Research Society. Alpay can be reached at the Department of Materials Science and Engineering, University of Connecticut, Storrs, CT, USA; tel. 860486-4621 and email p.alpay@ims.uconn.edu.

Joseph Mantese is a Research Fellow at United Technologies Corporation's Research Center (UTRC). His honors include an R\&D 100 Award, UTRC's Outstanding Achievement Award, two General Motors Campbell Awards, inductance into Delphi Corporation's Hall of Fame, a Wayne State University Socius Collegii Award, and inductance into the Connecticut Academy of Science and Engineering (CASE). He is the holder of 37 patents pertaining to electronic materials, sensors, MEMS, and components. He has authored over 95 publications on ferroic materials. He can be reached at United Technologies Research Center, 411 Silver Lane, East Hartford, CT, USA; email mantese@utrc.utc.com.

Susan Trolier-McKinstry is a Professor of Ceramic Science and Engineering and Director of the Nanofabrication Laboratory at The Pennsylvania State University (Penn State). Her main research interests include dielectric and piezoelectric thin films, texture development in bulk ceramic piezoelectrics, and spectroscopic ellipsometry. She is a Fellow of the American Ceramic Society and IEEE, an academician of the World

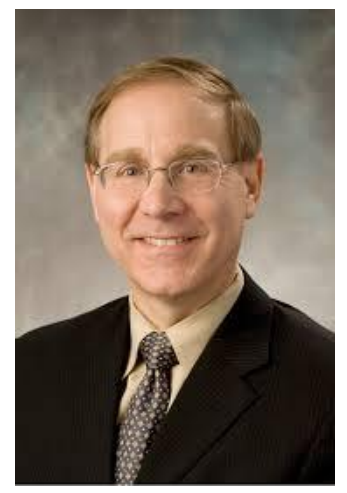
Academy of Ceramics, and a member of the Materials Research Society. She can 
be reached at The Pennsylvania State University, N-227 Millennium Science Complex, University Park, PA 16802, USA; tel. 814-863-8348, fax 814-865-7173, and email STMcKinstry@psu.edu.

Qiming Zhang is a Distinguished Professor of Engineering at The Pennsylvania State University. The research areas in his group include fundamentals and applications of electronic and electroactive materials. During his more than 20 years at Penn State, he has conducted research covering actuators, sensors, transducers, dielectrics and charge storage devices, polymer thin-film devices, polymer MEMS, electrocaloric-effect and solid-state cooling devices, and electro-optic and photonic devices. He has over 380 publications and 15 patents in these areas. His group discovered and developed a series of electroactive polymer actuators with high strain generation capabilities. More recently, his group also developed and discovered a giant electrocaloric effect in both ferroelectric polymers and ceramics. He can be reached at The Pennsylvania State University, N-219 Millennium Science Complex, University Park, PA 16802, USA; tel. 814-8638994, email qxz1@ psu.edu.

Roger Whatmore is Emeritus Professor at University College Cork and senior research associate at Imperial College London. He earned his $\mathrm{PhD}$ (1977) and ScD (2003) degrees from Cambridge University, Cambridge, UK. He worked on the applications of ferroelectric materials at Plessey/GEC Marconi Laboratories, Towcester, UK (1976-1994); was appointed Professor of Engineering Nanotechnology at Cranfield University, Cranfield, UK (1994-2005); and was CEO of Tyndall National Institute, Cork, Ireland (2006-2012). He was awarded GEC's Nelson Gold Medal and the Prince of Wales' Award for Innovation in 1993 and the Griffith Medal and Prize for Excellence in Materials Science in 2003. He is a Fellow of the Royal Academy of Engineering (FREng), Member of the Royal Irish Academy (MRIA); Fellow of the Irish Academy of Engineering (FIAE); 
Fellow of the Institute of Physics (UK) (FInstP); Fellow of the Institute of Materials, Minerals and Mining (FIMMM); and Chartered Engineer (UK) (CEng). He has published more than 300 articles and more than 40 patents. He can be reached at Department of Materials, Faculty of Engineering, Imperial College London, London, SW7 2AZ, UK; email r.whatmore@imperial.ac.uk. 